\title{
Assessing the feasibility of heart rate variability as an objective indicator of anxiety in older adults with dementia living in care homes
}

Milena A. Quinci ${ }^{1,2}$ and Arlene J. Astell ${ }^{1,3,4^{*}}$ (1)

\begin{abstract}
Objective: Anxiety is reportedly prevalent in older adults with dementia living in care homes and, within this population, is most often assessed through caregiver reports. Heart rate variability (HRV) is a physiological indicator of autonomic function, whereby reduced vagally-mediated HRV is associated with a variety of anxiety symptoms and disorders. This study evaluates the feasibility of collecting HRV data within this population, presents HRV data for older adults with dementia living in a care home, and examines HRV in the context of self-reported anxiety. These data were collected during a larger study examining an exercise intervention.
\end{abstract}

Results: HRV data, in the form of log-transformed root mean square of the successive differences (InRMSSD), were in line with transformed data from previous research. These data provide a promising direction for the use of wrist-worn devices in future HRV research with people living with dementia in care homes.

Keywords: Dementia, Anxiety, heart rate variability, long-term care

\section{Introduction}

Anxiety disorders are characterized by excessive worry, restlessness, and irritability [1]. Physiological hallmarks include increased heart rate and respiratory frequency and reduced parasympathetic activity [2]. Anxiety disorders are common among people with dementia [3], with a high reported prevalence within the care home population [4]. Caregiver observations or reports are commonly used to assess anxiety in people with dementia but have a low correlation with self-reported symptoms [5].

Heart rate variability (HRV), a physiological index used to assess autonomic nervous system (ANS) activity, measures the variability in time between two consecutive

\footnotetext{
*Correspondence: a.astell@reading.ac.uk

${ }^{1}$ School of Psychology \& Clinical Sciences, University of Reading, Reading RG6 7BE, UK

Full list of author information is available at the end of the article
}

heartbeats, also referred to as RR-intervals [6]. Traditionally assessed using an electrocardiogram (ECG), wearable devices such as chest straps and wrist-worn monitors are also gaining popularity [7]. HRV data are most commonly analysed using time-domain and frequency-domain measures. Time-domain measures, which quantify the variability in RR-intervals, include standard deviation of all R-R intervals (SDNN), percentage of consecutive regular sinus RR-intervals over $50 \mathrm{~ms}$ (pNN50), and root mean square of the successive differences (RMSSD) [8]. Frequency-domain measures, which quantify oscillatory components into different frequency bands [9], include ultra-low frequency (ULF), very-low frequency (VLF), low frequency (LF), high frequency (HF), and low frequency/high frequency ratio (LF/HF) [8]. Each measure of HRV is associated with different autonomic branches, with RMSSD and HF indicating parasympathetic activity [6]. Lower parasympathetic, or vagally-mediated, HRV 
has been associated with a variety of anxiety symptoms and disorders [10].

The overall goal of this novel project is to present HRV data for older adults with dementia, specifically living in a care home. More specifically, this project aims to (1) evaluate the feasibility of collecting HRV data within the dementia care home population; (2) investigate autonomic functioning, as measured through HRV, in the older adults with dementia living in a care home; and (3) discuss these HRV results in the context of self-reported anxiety.

\section{Main text Methods}

Ten participants ( 3 males, 7 females) with a mean age of $90(S D=5.80$; Table 1) were recruited from a specialized dementia long-term care home. Age, dementia diagnosis, mental health diagnoses (if any), and current medications were extracted from records. Participants' cognitive functioning was assessed using the Montreal Cognitive Assessment (MoCA) [11], which confirmed that all participants had cognitive impairments (indicated by a MoCA score of $<26 / 30$ ). The Hospital Anxiety and Depression Scale anxiety subset (HADS-A) was used to assess participants' anxiety, with a score of greater than $10 / 21$ considered abnormal as per the authors' instructions [12]. This measure was chosen as it is a short assessment used previously to evaluate self-reported anxiety in PWD [13]. HRV data were collected using the Zoom HRV wrist-worn monitor. A wrist monitor was used as it is completely non-invasive and easily portable [7]. The data were saved to the Elite HRV iPhone application. Kubios HRV Standard software was used for the analysis of the RR-interval data.
Data were collected at the care home, in either a small library or lounge. The wrist-worn monitor was placed on participants' non-dominant wrist to reduce the residual effects of daily activities frequently performed using the dominant hand [14] on the data. Participants were asked to sit in an upright position, keep their eyes open, and remain still and quiet during this portion of data collection. Despite these instructions, most participants moved occasionally or engaged in conversation with a staff member or volunteer. RR-interval recordings were taken after participants had been seated for approximately one minute. Two recordings of RR-interval data were collected from each participant.

Following HRV data collection, the Hospital Anxiety and Depression Scale (HADS) statements and response options were read aloud to the participants as many of them had poor eyesight which interfered with their ability to read the statements. Participants were asked to articulate their response to each statement aloud. Since the HADS assessment contained statements regarding sensitive subject matter, special attention was paid to the participants' well-being during the administration of this assessment. Subsequently, a second researcher administered the MoCA as per the administration guidelines.

\section{Data analysis}

Two shorter epochs, rather than one longer one, were collected due to the limitation of the Zoom HRV device and to minimize non-stationarities in the data [15]. These epochs ranged from 65 to $156 \mathrm{~s}(M=126.1)$. Prior to analysis, a few of the epochs were shortened due to signal loss. The range of epoch times remained the same, but the mean differed slightly $(M=125.5)$.

Artefact correction was performed using thresholdbased artefact correction. Each epoch was corrected

Table 1 Participant demographic information

\begin{tabular}{|c|c|c|c|c|}
\hline Participant ID & Age & Dementia diagnosis & $\begin{array}{l}\text { Mental health diagnoses } \\
\text { (if any) }\end{array}$ & $\begin{array}{l}\text { MoCA } \\
\text { score (out } \\
\text { of } 30 \text { ) }\end{array}$ \\
\hline P1 & 97 & Dementia & - & 4 \\
\hline P2 & 88 & Dementia & Anxiety & 0 \\
\hline P3 & 96 & Alzheimer's & - & 15 \\
\hline P4 & 96 & Alzheimer's & - & 8 \\
\hline P5 & 88 & Dementia & - & 6 \\
\hline P7 & 95 & Dementia & - & 7 \\
\hline P8 & 85 & Mixed and Vascular Dementia & Depression & 10 \\
\hline P9 & 88 & Alzheimer's and Vascular Dementia & - & 9 \\
\hline P10 & 87 & Dementia & - & 3 \\
\hline P11 & 80 & Vascular Dementia & - & 20 \\
\hline Mean (SD) & $90(5.80)$ & - & - & $8.2(5.54)$ \\
\hline
\end{tabular}


using a different threshold strength, as there was variation in the quality of the RR-interval data between different participants and epochs. The lowest strength threshold that allowed for the identification and correction of the most artefacts was chosen. In a majority of the epochs, the percentage of beats corrected did not exceed $5 \%$ [16]. Some epochs required more rigorous corrections. Just over $5 \%$ of beats were corrected in two of the epochs [17]. The artefact corrected data were detrended using the smoothn priors method [18] with a lambda value of 500 [16]. The data were then analysed in the time domain to produce RMSSD values. The two RMSSD values per participant, in units of milliseconds (ms), were prorated to equal time intervals of $60 \mathrm{~s}$ to correct for differing epoch durations [19] and averaged so each participant had one RMSSD value.

The Shapiro-Wilk test was run for the averaged, prorated RMSSD values to ensure normal distribution. The data were not normally distributed $(p<0.05)$. To correct for this, the data were transformed using the natural $\log$ function (ln) [6]. The log transformed RMSSD (lnRMSSD) values were normally distributed, $W(10)=0.927, p>0.05$.

\section{Results}

To our knowledge, there are no data reporting average HRV for the dementia care home population to use as a direct means of comparison. Table 2 summates data from past studies investigating time-domain HRV in older adults of a variety of ages and physical capabilities. These indicate a range for mean log transformed RMSSD data for older adults between 3.05 and 3.30. The mean lnRMSSD from the participants in this study was 3.17 (Table 3).

\section{Table 3 Participant HRV and self-reported anxiety}

\begin{tabular}{llll}
\hline $\mathbf{N}=\mathbf{1 0}$ & & & \\
\hline Participant ID & RMSSD & InRMSSD & HADS-A \\
\hline P1 & 13.21 & 2.58 & 6 \\
P2 & 8.70 & 2.16 & 12 \\
P3 & 92.43 & 4.53 & 4 \\
P4 & 11.23 & 2.42 & 3 \\
P5 & 5.14 & 1.64 & 2 \\
P7 & 31.31 & 3.44 & 4 \\
P8 & 98.99 & 4.59 & 4 \\
P9 & 78.57 & 4.36 & 2 \\
P10 & 25.32 & 3.23 & 7 \\
P11 & 15.98 & 2.77 & 9 \\
M(SD) & $38.09(36.95)$ & $3.17(1.04)$ & 5.30 (3.23) \\
\hline
\end{tabular}

Table 2 Articles reporting time-domain analysed HRV for older adults

\begin{tabular}{|c|c|c|c|c|c|c|c|}
\hline Author and Date & $\mathbf{N}$ & Population & Dementia & $\begin{array}{l}\text { Age range } \\
\text { or Mean age } \\
\text { (years) }\end{array}$ & HRV recording device & RMSSD (ms) & InRMSSD (ms) \\
\hline Albinet et al. (2010) [20] & 24 & Sedentary older adults & No & 70.7 & $\begin{array}{l}\text { Polar Wearlink }{ }^{\circledR} \text { Wind } \\
\text { transmitter belt }\end{array}$ & $23.7-26.9$ & $3.05-3.09$ \\
\hline \multirow[t]{2}{*}{$\begin{array}{l}\text { Almeida-Santos et al. } \\
\text { (2016) [21] }\end{array}$} & 1743 & $\begin{array}{l}\text { Functionally independ- } \\
\text { ent adults with satisfac- } \\
\text { tory }\end{array}$ & No & $40-100$ & ECG & 30.22 & 3.3 \\
\hline & 169 & Cognition & & $\geq 80$ & & 33 & NR \\
\hline \multirow[t]{2}{*}{$\begin{array}{l}\text { de Vilhena Toledo and } \\
\text { Junqueira (2008) [22] }\end{array}$} & 22 & $\begin{array}{l}\text { Older adults with } \\
\text { probable Alzheimer's } \\
\text { disease }\end{array}$ & Yes & $60-87$ & ECG & 14.0 & NR \\
\hline & 24 & Healthy older adults & No & $60-91$ & & 17.6 & NR \\
\hline \multirow[t]{3}{*}{ Kasanuki et al. (2015) [23] } & 30 & $\begin{array}{l}\text { Patients with probable } \\
\text { dementia with Lewy } \\
\text { bodies }\end{array}$ & Probable & & ECG & 14.2 & NR \\
\hline & 3 & $\begin{array}{l}\text { Patients with Alzheimer's } \\
\text { disease }\end{array}$ & Not specified & 79.6 & & 27.9 & NR \\
\hline & 20 & Healthy elderly adults & No & 77.2 & & 25.4 & NR \\
\hline Kurita et al. (2006) [24] & 12 & $\begin{array}{l}\text { Elderly adults hospi- } \\
\text { talized for cerebral } \\
\text { vascular disease and } \\
\text { dementia }\end{array}$ & Yes & 88 & ECG & 19.4 & NR \\
\hline Zulfiqar et al. (2010) [25] & 20 & Health older adults & No & 80-99 & Holter monitor & 30 & NR \\
\hline
\end{tabular}




\section{Discussion}

This study aimed to assess the feasibility of collecting HRV data in the dementia care home population. The few existing studies exploring HRV in people with dementia found that this population exhibits reduced HRV [22-24, 26]. Reduced HRV has also been found in older people without dementia who exhibit cognitive impairments [8]. Given that reduced autonomic functioning is associated with dementia, it is important to identify a normal HRV range for older adults with cognitive impairments. Our log-transformed mean RMSSD data fell between the reported mean InRMSSD of 3.05 by Albinet et al. [20] and 3.30 by Almeida-Santos et al.[21], suggesting that our participants exhibited a similar level of parasympathetic control to older adults without cognitive impairments described in previous studies. Data presented in this paper adds to the current body of literature assessing autonomic functioning in older adults with dementia.

This study also investigated the use of wrist-worn devices, which have been previously used to explore autonomic functioning in older adults with dementia over the course of their daily routine [27, 28]. Despite the promising implications of wrist-worn devices, there is limited literature that explores the use of these devices in a clinical context [7]. This paper may be among the first to report time-domain analysed HRV values collected using a wrist-worn device for PWD. Thus, our data adds to the growing body of literature exploring the use of wrist-worn devices for clinical purposes.

Based on past literature indicating a high level of anxiety (up to 70\%) in people with dementia [3], it was expected that the majority of participants in the current study would have anxiety. However, only one participant received a HADS-A score between eight and ten, which is classified as borderline abnormal, and one participant received a score that was considered abnormal (12). This same participant was the only one who had a previous diagnosis of anxiety in her medical records. This suggests that, though self-report measures of anxiety are often overlooked for caregiver reports [3], these measures may provide a reliable assessment of anxiety within the dementia care home population. These findings indicate a need for the prevalence of anxiety within this population to continue to be evaluated. Given the relationship between HRV and anxiety described in previous literature [10], future studies should explore the relationship between anxiety and HRV, collected using wrist-worn devices, to see if HRV could be used as an objective indicator of the prevalence of anxiety in the population living in care homes with dementia.

\section{Limitations}

A small sample size could have hindered the detection of any significant findings of a relationship between anxiety and HRV. This is a common problem for HRV studies, which are often underpowered [6]. A second limitation was participants' prescribed medications. Antidepressant, antipsychotic, antihypertensive, and cardio-related medications have been said to affect HRV. All participants were on at least one medication, and seven were taking at least one medication that fell into one of the categories indicated by Laborde et al. (2017) as exclusionary. A third limitation was the short epochs of HRV data that were able to be collected by the Zoom HRV per each recording. The device was chosen as it was the least invasive device available that had the ability to measure and export HRV data and had been used in other studies [29]. Although, this is a sufficient amount of data to accurately assess RMSSD [6], all the epochs were of different lengths as the device stops recording when the signal is lost, making it impossible to control the length of each epoch. Future studies should continue to evaluate different wrist-worn monitors that are able to record more consistent epochs of RR-interval data. Overall the study demonstrated the feasibility of collecting HRV data in a dementia care home environment in a manner that was acceptable to the residents. This shows great promise for future research studies and clinical practice to accurately detect the presence of anxiety in this population and intervene to reduce symptoms and improve wellbeing of people living with dementia in care homes.

\section{Abbreviations \\ ANS: Autonomic Nervous System; HADS: Hospital Anxiety and Depression Scale; HF: High Frequency; HRV: Heart Rate Variability; LF: Low Frequency; LF/ HF: Low frequency/high frequency ratio; InRMSSD: Log transformed RMSSD; MoCA: Montreal Cognitive Assessment; RMSSD: Root mean square of the successive differences; SDNN: Standard Deviation of R-R intervals; R-R interval: Variability in time between two consecutive heartbeats; ULF: Ultra-low fre- quency; VLF: Very-low frequency low frequency.}

\section{Acknowledgements \\ We are grateful to the residents and staff who contributed to this study as well as to Simon Morrison for his support during data collection. The work of the second author was partly supported by the Ontario Shores Research Chair in Dementia Well-being.}

\section{Authors' contributions}

Both authors made substantial contributions to the conception and design of the study. MQ collected and analysed the data, both worked on the interpretation of data, MQ drafted the work and AJA substantively revised it. Both authors read and approved the final manuscript.

\section{Funding}

Not applicable.

Availability of data and materials

The datasets used and/or analysed during the current study are available from the corresponding author on reasonable request. 


\section{Ethics approval and consent to participate}

This study was approved by the Psychology and Clinical Language Sciences School Research Ethics Committee (SREC) and the University of Reading Research Ethics Committee (UREC). Capacity to consent was assessed in accordance with the Mental Capacity Act 2005, which involves explaining the purpose of the study and what will be involved and assessing potential participants understanding of what has been explained. Potential participants who answered the questions were asked for written or oral consent, which was witnessed by a non-involved third party. Potential participants who were unable to respond to the questions were excluded. Participants continuing consent was confirmed at each visit.

\section{Consent for publication}

\section{Not applicable.}

\section{Competing interests}

The authors declare that they have no competing interests.

\section{Author details}

${ }^{1}$ School of Psychology \& Clinical Sciences, University of Reading, Reading RG6 7BE, UK. ${ }^{2}$ Centre for Cognitive \& Brain Health, Northeastern University, Boston, MA, USA. ${ }^{3}$ Department of Occupational Sciences \& Occupational Therapy and Department of Psychiatry, University of Toronto, Toronto, Canada. ${ }^{4}$ KITE, University Health Network, Toronto, Canada.

Received: 8 September 2020 Accepted: 20 January 2021 Published online: 05 February 2021

\section{References}

1. American Psychiatric Association. Diagnostic and statistical manual of mental disorders. 5th ed. Arlington: American Psychiatric Association; 2013.

2. Thayer JF, Friedman BH, Borkovec TD. Automatic characteristics of generalized anxiety disorder and worry. BiolPsychiat. 1996;39(95):255-66. https:// doi.org/10.1016/0006-3223(95)00136-0.

3. Seignourel PJ, Kunik ME, Snow L, Wilson N, Stanley M. Anxiety in dementia: a critical review. ClinPsychol Rev. 2008;28(7):1071-82. https://doi. org/10.1016/j.cpr.2008.02.008.

4. Goyal AR, Bergh S, Engedal K, Kirkevold M, Kirkevold $\varnothing$. The course of anxiety in persons with dementia in Norwegian nursing homes: a 12-month follow-up study. J Affect Disord. 2018;235:117-23. https://doi.org/10.1016/j. jad.2018.04.015.

5. Gibbons LE, Teri L, Logsdon RG, McCurry SM. Assessment of anxiety in dementia: An investigation into the association of different methods of measurement. J Geriatr Psychiatry Neurol. 2006;19(4):202-8. https://doi. org/10.1177/0891988706292758.

6. Laborde S, Mosley E, Thayer JF. Heart rate variability and cardiac vagal tone in psychophysiological research—Recommendations for experiment planning, data analysis, and data reporting. Front Psychol. 2017;8:1-18. https:// doi.org/10.3389/fpsyg.2017.00213.

7. Graham SA, Jeste DV, Lee EE, Wu TC, Tu X, Kim HC, Depp CA. Associations between heart rate variability measured with a wrist-worn sensor and older adults' physical function: observational study. JMIR mHealth and uHealth. 2019. https://doi.org/10.2196/13757.

8. Forte $\mathrm{G}$, Favieri F, Casagrande M. Heart rate variability and cognitive function: a systematic review. Front Neurosci. 2019;13:710. https://doi.org/10.3389/ fnins.2019.00710.

9. Stein PK, Bosner MS, Kleiger RE, Conger BM. Heart rate variability: a measure of cardiac autonomic tone. Am Heart J. 1994;127(5):1376-81. https://doi. org/10.1016/0002-8703(94)90059-0.

10. Chalmers JA, Quintana DS, Abbott MJA, Kemp AH. Anxiety disorders are associated with reduced heart rate variability: a meta-analysis. Front Psychiatry. 2014;5:1-11. https://doi.org/10.3389/fpsyt.2014.00080.

11. Nasreddine Z, Charbonneau S, Cummings JL. The Montreal Cognitive Assessment, MoCA: a brief screening tool for mild cognitive impairment. J Am GeriatrSoc. 2005;53(4):695-9. https://doi.org/10.111 1/j.1532-5415.2005.53221.x.

12. Zigmond AS, Snaith RP. The hospital anxiety and depression scale. ActaPsychiatrScand. 1983;67(6):361-70. https://doi.org/10.1111/j.1600-0447.1983. tb09716.x.
13. Creighton AS, Davison TE, Kissane DW. The psychometric properties, sensitivity and specificity of the geriatric anxiety inventory, hospital anxiety and depression scale, and rating anxiety in dementia scale in aged care residents. Aging Mental Health. 2019;23(5):633-42. https://doi. org/10.1080/13607863.2018.1439882.

14 Sarabia JA, Rol MA, Mendiola P, Madrid JA. Circadian rhythm of wrist temperature in normal-living subjects. A candidate of new index of the circadian system. PhysiolBehav. 2008;95(4):570-80. https://doi.org/10.1016/j. physbeh.2008.08.005

15. Berntson GG, Bigger JTJ, Eckberg DL, Grossman P, Kaufmann PG, Malik M, Nagaraja HN, Porges SW, Saul JP, Stone PH, Van Der Molen MW. Heart rate variability: origins, methods, and interpretive caveats. Psychophysiology. 1997;34(6):623-48.

16. Tarvainen, M. P., Lipponen, J. A., Niskanen, J., \& Ranta-aho, P. O. Kubios HRV user's guide, 2017; p. 1-58. https://doi.org/10.1016/j.enconman.2005.10.016

17. Sandercock GRH, Grocott-Mason R, Brodie DA. Changes in short-term measures of heart rate variability after eight weeks of cardiac rehabilitation. ClinAuton Res. 2007:17(1):39-45. https://doi.org/10.1007/s10286-007-0392-5.

18. Tarvainen MP, Ranta-aho PO, Karjalainen PA. An advanced detrending method with application to HRV analysis. IEEE Trans Biomed Eng. 2002:49(2):172-5. https://doi.org/10.1109/10.979357.

19. Schulz SM, Alpers GW, Hofmann SG. Negative self-focused cognitions mediate the effect of trait social anxiety on state anxiety. Behav Res Ther 2008:46(4):438-49. https://doi.org/10.1016/j.brat.2008.01.008.

20. Albinet CT, Boucard G, Bouquet CA, Audiffren M. Increased heart rate variability and executive performance after aerobic training in the elderly. Eur J ApplPhysiol. 2010;109(4):617-24. https://doi.org/10.1007/s0042 1-010-1393-y.

21. Almeida-Santos MA, Barreto-Filho JA, Oliveira JLM, Reis FP, da Cunha Oliveira CC, Sousa ACS. Aging, heart rate variability and patterns of autonomic regulation of the heart. Arch GerontolGeriatr. 2016;63:1-8. https://doi. org/10.1016/j.archger.2015.11.011.

22. de Vilhena Toledo MA, Junqueira LFJ. Cardiac sympathovagal modulation evaluated by short-term heart interval variability is subtly impaired in Alzheimer's disease. GeriatrGerontollnt. 2008;8(2):109-18. https://doi.org/10.111 1/j.1447-0594.2008.00456.x.

23. Kasanuki K, Iseki E, Fujishiro H, Ando S, Sugiyama H, Kitazawa M, Chiba Y, Sato $\mathrm{K}$, Arai $\mathrm{H}$. Impaired heart rate variability in patients with dementia with Lewy bodies: Efficacy of electrocardiogram as a supporting diagnostic marker. Parkinsonism RelatDisord. 2015;21(7):749-54. https://doi. org/10.1016/j.parkreldis.2015.04.024.

24. Kurita A, Takase B, Okada K, Horiguchi Y, Abe S, Kusama Y, Atarasi H. Effects of music therapy on heart rate variability in elderly patients with cerebral vascular disease and dementia. J Arrhythmia. 2006;22(3):161-6. https://doi. org/10.1016/S1880-4276(06)80014-1.

25. Zulfiqar U, Jurivich DA, Gao W, Singer DH. Relation of high heart rate variability to healthy longevity. Am J Cardiol. 2010;105(8):1181-5. https://doi. org/10.1016/j.amjcard.2009.12.022.

26. da Silva VP, Oliveira BRR, Mello RGT, Moraes H, Daslandes AC, Laks J. Heart rate variability indexes in dementia: a systematic review with a quantitative analysis. CurrAlzheimer Res. 2018;15(1):80-8. https://doi.org/10.2174/15672 05014666170531082352.

27. Alam, M. A. U., Roy, N., Holmes, S., Gangopadhyay, A., \& Galik, E. Automated Functional and Behavioral Health Assessment of Older Adults with Dementia. Proceedings - 2016 IEEE 1st International Conference on Connected Health: Applications, Systems and Engineering Technologies, CHASE 2016, 140-149. https://doi.org/10.1109/CHASE.2016.16

28 Fuji S, Tanioka T, Yasuhara Y, Sato M, Saito K, Purnell MJ, Locsin R, Yasui T. Characteristic autonomic nervous activity of institutionalized elders with dementia. Open J Psychiatry. 2016;6(1):34-49. https://doi.org/10.4236/ojpsy ch.2016.61004.

29. Kamioka E. Emotions detection scheme using facial skin temperature and heart rate variability. MATEC Web Conf. 2019. https://doi.org/10.1051/matec conf/201927702037.

\section{Publisher's Note}

Springer Nature remains neutral with regard to jurisdictional claims in published maps and institutional affiliations. 